\section{A Comment on Positive Theory}

Harry Eckstein

University of California, Irvine

The Association allows its members to identify themselves as "positive theorists." I am a member who so identifies himself. Over several years, numerous political scientists (not themselves positive theorists) have asked me (sarcastically) whether positive theory is the opposite of "negative" theory. In each case, to avoid heaping sarcasm upon sarcasm, I answered that the word positive, in this case, referred to positivism, as in Conte's Positive Philosophy and Positive Polity. It referred to the assignment of a central role to observing phenomena and discovering the laws that relate them, and doing so gradually and laboriously, and, as Comte already understood and Weber makes crystal clear, without ever coming to final Truth. It did not refer to plus or minus signs.

What I left out is that the word "positive " was in fact used early on in contradistinction to "negative" thought. But it may be useful to do so impersonally, for the information of those who seem unfamiliar with the ideas of our founders.

The early positivists understood that human beings need to make sense of experience. They also understood the arduousness of doing so by theory based on and tested by observation, especially in the case of phenomena more complex than, say, astronomical motion. This, they argued, accounted for resorts to pseudoexplanations: to "theological" or "metaphysical" mumbo-jumbo. That sort of thought was "negative" thought--negative, because not resting on solid bases and likely to do more harm than good.

The early positivists were convinced that positive thought would gradually triumph over negative, fetishistic thinking, in all fields -spreading slowly from the simplest to the most complex phenomena. Surely, they have been substantially right, although they underestimated the continued appeals of high-flown obscurantism in the social sciences.
"Positive" thought also had a secondary meaning early on, related to its primary. meaning. It arose in the wake of the French Revolution, and involved a reaction against that revolution's guiding idea: that utopian transformation could be achieved by simple "negative" action: getting rid of feudal or similar constricting relations. One reaction to the revolution's fallure to make a "new beginning" simply by removing old obstacles, was the reactionary mumbo-jumbo of men like De Mastre. Comte, positivism's acknowledged founder, empathized with such disillusioned reactions, but he did not join in them. What was needed was not regress to "negative" thinking but positive understanding, for the sake of the gradual refor. mation of society. Such a reformation, to succeed, required the solidity of positive understanding of the actual nature and relations of phenomena. Anything elsereactionary or radical-was negativistic: "nonsense upon stilts," Bentham called it.

Positive thought thus was oriented to efficacious social betterment from the outset. But it was also reconciled to the necessity of its being gradualistic and to the need to work with the nature of people and societies to achieve it, not with fanciful imaginings of them; above all, not with baseless dogmas, like the old theologies. even if secularized into pseudo-theoretical systems.

The positivist position may be debatable, but I only want to bring out here that the idea of "negative theory" is not in the least a joke and that "positive theory" has historically rooted meaning. It is, in fact, a singularly well-chosen label, as the contrary of negative thought. 